EGU2020-5113, updated on 27 Mar 2020

https://doi.org/10.5194/egusphere-egu2020-5113

EGU General Assembly 2020

(c) Author(s) 2020. This work is distributed under

the Creative Commons Attribution 4.0 License.

\title{
The impact of on-site wastewater effluent on rural karstified aquifers
}

\author{
Luka Vucinic $^{1,2}$, David O'Connell ${ }^{1,2}$, Donata Dubber ${ }^{1}$, Patrice Behan ${ }^{5}$, Quentin Crowley ${ }^{2,3,4}$, \\ Catherine Coxon ${ }^{2,3,4}$, and Laurence Gill ${ }^{1,2}$ \\ ${ }^{1}$ Trinity College Dublin, Department of Civil, Structural and Environmental Engineering, Dublin (vucinicl@tcd.ie) \\ ${ }^{2}$ Irish Centre for Research in Applied Geosciences (iCRAG), Dublin \\ ${ }^{3}$ Trinity College Dublin, School of Natural Sciences, Department of Geology, Dublin \\ ${ }^{4}$ Trinity College Dublin, Centre for the Environment, Dublin \\ ${ }^{5}$ Technological University Dublin, School of Chemical and Pharmaceutical Sciences, Dublin
}

Karst aquifers are exceptionally vulnerable to pollution and may be impacted by multiple contamination sources. In rural and suburban areas, human wastewater effluent from on-site domestic wastewater treatment systems (DWTSs) and agricultural sources are the most significant threats to groundwater quality. It has been estimated that around 2.8 billion people worldwide rely on DWTSs for treating domestic wastewater. As karst groundwater is a major source of drinking water for at least one-quarter of the world's population it makes protection and management of karst aquifers extremely important. These aquifer systems are highly complex and challenging to understand, especially with regards to the fate and transport of contaminants through such systems. Thus, significant knowledge gaps exist with respect to linking contaminants with the origins of pollution and quantifying different pollution impacts on groundwater quality in karst environments.

In this paper, a novel approach for investigation of the impact of contaminants from DWTS effluent on rural karstified aquifers using a range of source-specific tracers is proposed, as it is extremely difficult to distinguish between agricultural and DWTS effluent pollution using only traditional water quality parameters or any single environmental marker. Domestic wastewater is primarily discharged from toilets, washing machines, showers and dishwashers, but even after onsite wastewater treatment processes a large number of different contaminants, including sourcespecific ones, can still reach the groundwater and wider environment. One example are microplastic particles which are found with other solid materials in the wastewater effluent principally due to household washing and cleaning processes. Investigations of microplastic occurrences in groundwater systems are very rare but several karst springs in the west of Ireland have been sampled during this study for quantification and identification of microplastic particles using Fourier-transform infrared spectroscopy (FTIR). Many of these particles were successfully linked to human wastewater on the basis of their physical and chemical properties and/or adsorbed/absorbed pollutants. The overall numbers of microplastics and numbers of householdderived microplastic particles were linked to other well-known indicators of human contamination 
such as fluorescent whitening compounds (FWCs) and specific anion ratio signatures ( $\mathrm{Cl}: \mathrm{Br})$. Our results show a significant correlation between microplastics and detected FWC signals at different karst springs over time, which suggests the majority of found microplastic particles to be from DWTS effluent. Notably, certain limitations were found and furthermore understood in terms of the capability of $\mathrm{Cl}: \mathrm{Br}$ ratio method in determining human wastewater impacts on karst groundwater. Additionally, we have found that faecal sterol and stanol concentrations, as sourcespecific faecal markers, and their ratios can very successfully differentiate and quantify DWTS effluent pollution and agricultural faecal contamination at karst springs due to rapid and extensive transport of these contaminants particularly through the karst conduit networks. 